\title{
Study on the influence of alumina nano- methanol fluid on the performance, combustion and emission of DMDF diesel engine
}

\author{
Zenghui $\mathrm{Yin}^{1}$, Jing $\mathrm{Hao}^{1}$, and Jiangjun $\mathrm{Wei}^{2}$,* \\ ${ }^{1}$ China Automotive Technology \&Research Center Co.Ltd, China \\ ${ }^{2}$ Hefei University of Technology, China
}

Keywords: diesel engine, methanol, nano $\mathrm{Al}_{2} \mathrm{O}_{3}$ combustion, emission.

\begin{abstract}
With the increasingly strict domestic emission regulations, how to reduce diesel emission without affecting its output power has become a hot and important research topic. Due to their unique physical and chemical properties, the combined use of methanol and $\mathrm{Al}_{2} \mathrm{O}_{3}$ nanoparticles plays a unique role in promoting combustion and reducing emissions. In this study, $\mathrm{Al}_{2} \mathrm{O}_{3}$ methanol nanofluid fuel was injected into the inlet and diesel fuel was injected into the cylinder to explore the influence of $\mathrm{Al}_{2} \mathrm{O}_{3}$ nanoparticles on the performance, combustion and emissions of diesel methanol dual fuel (DMDF) entered. The experienced results showed that with the addition of $\mathrm{Al}_{2} \mathrm{O}_{3}$ nanoparticles in methanol, the peak pressure and heat release rate in the cylinder of the diesel engine were improved, the combustion delay period and the combustion duration were shortened, the fuel consumption rate was reduced by up to $10.8 \%$, and the braking thermal efficiency was increased by $12.11 \%$ at most. With the addition of $\mathrm{Al}_{2} \mathrm{O}_{3}$ nanoparticles, $\mathrm{NOx}, \mathrm{CO}, \mathrm{HC}$ and soot ratio emissions of the engine were reduced, among which the NOx reduction ratio was small, and the maximum reduction ratio of the last three was $28.82 \%$, $83.33 \%$ and $29.27 \%$ respectively.
\end{abstract}

\section{Introduction}

As we all know, diesel engines have the advantages of high thermal efficiency and good stability, and are widely used in transportation and industry. There is, however, an urgent need for technological improvement, accompanied by the emergence of a global shortage of oil production and serious pollution emissions such as diesel NOx and $\mathrm{PM}^{[1]}$. Many scholars inside and outside the country have done a lot of research on the fuel improvement of diesel engine. At present, there are two main ways to improve fuel, one is to develop clean alternative fuels, such as alcohols, natural gas ${ }^{[2]}$ and biodiesel ${ }^{[3]}$. The second is to add fuel additives to diesel oil to improve the quality of diesel oil, commonly used fuel additives are combustion accelerator, cetane number lifting agent and smoke elimination

* Corresponding author: wjiangjun@hfut.edu.c n 
agent. The combustion accelerators are mainly metal or non-metallic compounds, such as aluminum $(\mathrm{Al})$, silicon $(\mathrm{Si})$, cerium $(\mathrm{Ce})$ and so on.

Among the many kinds of alternative fuels, the raw materials for methanol production are very rich. the biomass such as coal, natural gas and wood, agricultural residues and microalgae, which are common in life, can be used to prepare methanol. In addition, the advantages of low evaporation temperature, high latent heat and low viscosity of methanol meet the test requirements. At present, there are two main ways to apply methanol to diesel engine: one is to mix methanol and diesel oil and then spray into cylinder for combustion. Huang etc. ${ }^{[4]}$ studied the emission and combustion characteristics of a single-cylinder diesel engine with stable diesel-methanol mixture fuel (18\% methanol content in the mixed fuel) were studied. Another is the DMDF mode of injecting methanol into the inlet and diesel in the cylinder. Yao Chunde ${ }^{[5]}$ studied the particulate characteristics and smoke correlation of intake premixed methanol/diesel dual fuel engine were studied. Zhang et al. ${ }^{[6]}$ showed that the diesel/methanol dual-fuel mode decreased $\mathrm{NO}_{\mathrm{X}}$ Smoke and PM emissions increased hydrocarbons $(\mathrm{HC})$, carbon monoxide $(\mathrm{CO})$ and nitrogen dioxide $(\mathrm{NO})_{2}$ ).

In addition, the rapid development of nano-particle material technology in recent years has also provided a new idea for the research of energy saving and emission reduction of diesel engines. Nanoparticles have a small size and a high surface-to-surface ratio, which can increase the heat transfer of fuel and increase the activity of combustion chemical reactions. Different kinds of nanoparticles have their unique chemical properties, researchers have carried out extensive research on nanoparticles in order to find the most suitable nanoparticles as fuel additives for marketing. Fang Ping et al ${ }^{[7]}$ found that $\mathrm{Ce}^{4+} / \mathrm{Ce}^{3+}$ valence states can be converted to each other when using $\mathrm{CeO}_{2}$ solid-based catalytic carbon particles in diesel engines, and they have storage/oxygen release capability and good thermal stability. Harish Venu et al. ${ }^{[8]}$ prepared $\mathrm{Al}_{2} \mathrm{O}_{3}$, ethanol and diesel as a mixed fuel, and found that the addition of $\mathrm{Al}_{2} \mathrm{O}_{3}$ particles increased carbon monoxide $(\mathrm{CO})$ emissions, reduced carbon dioxide $\left(\mathrm{CO}_{2}\right)$ emissions, delayed combustion (CD), and delayed ignition ( ID) time is shortened. Deepti Khatri et al. ${ }^{[9]}$ found that nano-silica $\left(\mathrm{SiO}_{2}\right)$ makes the braking thermal efficiency of water-diesel emulsion fuel increase, the specific fuel consumption is reduced, and the specific emissions of $\mathrm{CO}, \mathrm{HC}$ and soot are also reduced.

Current research on diesel engine combustion and emissions focuses on the blending of particulate matter with diesel fuel and the blending of alternative fuels with diesel fuel, but there are few studies that combine the two with each other (some studies choose water emulsified diesel fuel and blending Nanoparticles). For this reason, this article uses $\mathrm{Al}_{2} \mathrm{O}_{3}$ nanoparticles (low cost) were used as test fuel additive to make stable methanol-based nanofluid fuel with methanol by adding surfactant and ultrasonic stirring as inlet jet fuel, and diesel fuel was used as cylinder jet fuel. And explore $\mathrm{Al}_{2} \mathrm{O}_{3}$ effect of nanoparticles and methanol on combustion and emission performance of diesel fuel. The combination of the two will not increase the fuel cost too much, the results hope to provide theoretical reference for diesel fuel improvement.

\section{Test preparation, apparatus and methods}

\subsection{Fuel formulation}

The two basic fuels used in the test were commercially available $0 \#$ diesel oil and $99.9 \%$ analytical pure methanol, respectively. The physical and chemical characteristics are listed in Table 1.Also, the test will be $\mathrm{Al}_{2} \mathrm{O}_{3}$ nanoparticles as fuel additives, and their particulate matter parameters are listed in Table 2. Figure 1 is the transmission electron microscopy (TEM) photographs of the $\mathrm{Al}_{2} \mathrm{O}_{3}$ nanoparticles. from the figure, it can be seen that the 
nanoparticles present a rod-like morphology, and their surface contours are not smooth and round, with many subtle depressions or prominent sites. The average size is $32 \mathrm{~nm}$. from Image J image analysis

Table 1. Performance of base diesel and methanol.

\begin{tabular}{ccc}
\hline Performance & Diesel & Methanol \\
\hline Chemical formula & $\mathrm{C}_{12} \mathrm{C}-25$ & $\mathrm{CH}_{4} \mathrm{O}$ \\
Density $\left(\mathrm{g} / \mathrm{mL} @ 15^{\circ} \mathrm{C}\right)$ & 0.83 & 0.79 \\
Viscosity $\left(\mathrm{mm} 2 / \mathrm{s} @ 40^{\circ} \mathrm{C}\right)$ & 3.35 & 0.59 \\
cetane number $($ calculated cetane index) & 50.2 & $3-5$ \\
Boiling point $\left({ }^{\circ} \mathrm{C}\right)$ & $188-343$ & 64.8 \\
Flash Point $\left({ }^{\circ} \mathrm{C}\right)$ & 78 & 11 \\
Combustion temperature $\left({ }^{\circ} \mathrm{C}\right)$ & 235 & 470 \\
Evaporation heat $(\mathrm{kJ} / \mathrm{kg})$ & 260 & 1110 \\
Low calorific value $(\mathrm{MJ} / \mathrm{kg})$ & 42.8 & 20.3 \\
Oxygen content $(\mathrm{wt} \%)$ & 0 & 50 \\
stoichiometric air fuel ratio & 14.5 & 6.5 \\
\hline
\end{tabular}

Table 2. Technical specifications of nanoparticle additives for testing.

\begin{tabular}{c|c}
\hline Category & Aluminium oxide nanoparticles $\left(\mathrm{Al}_{2} \mathrm{O}_{3}\right)$ \\
\hline Average particle size/ $\mathrm{nm}$ & 30 \\
$\left.(\mathrm{~m})^{2} \mathrm{~g} .^{-1}\right)$ & 160 \\
Density $\left.(\mathrm{g} \square \mathrm{cm})^{-3}\right)$ & 3.9 \\
Pure purity & $3 \mathrm{~N}$ \\
Crystal type & Y phase \\
Physical phase & White powder \\
\hline
\end{tabular}

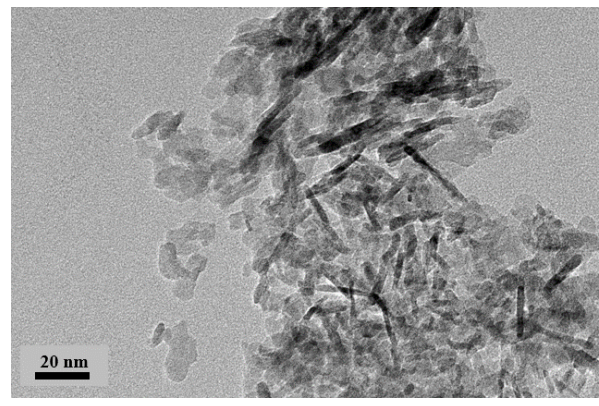

Fig. 1. Morphology of A12O3 nanoparticles used in the experiment.

In the experiment, $\mathrm{A} 12 \mathrm{O} 3$ nanoparticles were added to methanol to prepare three methanol-based nanofluid fuels with mass fractions of 25, 50, and $100 \mathrm{ppm}$, respectively. In order to ensure that the $\mathrm{A} 12 \mathrm{O} 3$ nanoparticles were evenly dispersed in methanol, they were stirred for 1 hour using an ultrasonic agitator. Because of the high specific surface and strong surface activity of nanoparticles make it easy to agglomerate and precipitate, the stability of methanol-based nanofluid fuel is poor. In order to prolong the stable storage time of fuel, the surface of nanoparticles was modified by a compound surfactant of $0.2 \%$ (composed of sodium dodecylbenzenesulfonate and cetyltrimethylammonium bromide at 1:1 mass ratio). A $1 \mathrm{~h}$ ultrasonic mixing method was used to mix the surfactant with 3 different concentrations of methyl nanofluid fuel.After measurement, this method can extend the stable placement time of the fuel to more than 15 days. 
The test was performed on a dual-fuel engine and the main parameters of the engine are listed in Table 3. Fig .2 is the test engine bench diagram. CMU3A dynamometer controller and CW25 eddy current dynamometer parameters are used to control the speed and torque of the diesel engine. The HR-CA-B combustion analyzer installed on the cylinder head is used to measure the pressure in the cylinder, and then calculate the instantaneous heat release rate from the cylinder pressure. Use the Dismoke 4000 smoke meter installed on the exhaust pipe to measure the soot emissions. Use the MEXA-584L gas analyzer to measure $\mathrm{CO}, \mathrm{NO}, \mathrm{NO} 2$ emissions, where NOX emissions are the sum of $\mathrm{NO}$ and $\mathrm{NO} 2$ emissions. Use the FCM-D flowmeter to measure the mass flow of methanol or methyl pure nano-fluid and diesel. The above test equipment and its accuracy are listed in Table 4. The schematic diagram of the engine bench is shown in Figure 2.

Table 3. Test engine specifications.

\begin{tabular}{lc}
\hline Engine specifications & \\
\hline Type of engine & Single bar four stroke \\
Combustion chamber type & Direct injection \\
aperture $\times$ stroke $(\mathrm{mm})$ & $100 \times 115$ \\
Emissions $(\mathrm{L})$ & 0.903 \\
Compression ratio & 17.5 \\
rated power $(\mathrm{kW}) /$ speed $(\mathrm{rpm})$ & $11.32 / 2200$ \\
$\mathrm{~s}$ & $50.6 / 1760$ \\
nozzle opening pressure $(\mathrm{MPa})$ & 18 \\
Fuel nozzles $(\mathrm{mm} /$ quantity) & $0.32 / 4$ \\
Fuel injection advance angle $\left({ }^{\circ}\right.$ CA BTDC) & 20 \\
Cooling mode & Forced circulation water cooling \\
\hline
\end{tabular}

Table 4. Accuracy of main test equipment.

\begin{tabular}{ccc}
\hline Name of equipment & Error & $(\%)$ of uncertainty \\
\hline Eddy current & $\mathrm{Nm} 0.01$ & \pm 0.1 \\
dynamometer & $\mathrm{kg} / \mathrm{h} 0.01$ & \pm 1 \\
Flowmeter sensor & $\mathrm{ppm} 0.01$ & \pm 1 \\
Combustion & ppm 0.01 & \pm 1 \\
analyzer & $0.001 \mathrm{FSN}$ & \pm 0.1 \\
Gas analyzer & & \\
Smoke meter & &
\end{tabular}

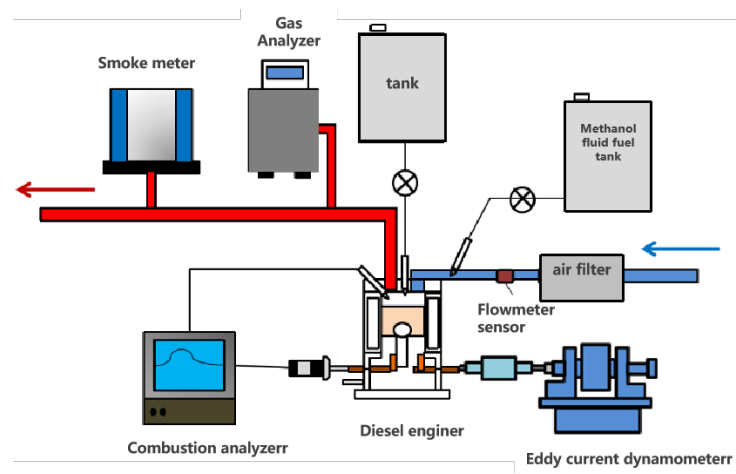

Figure 2. Experimental bench diagram.

In this test, D100 is used for pure diesel combustion. When the diesel engine is switched to DMDF mode, methanol/Al2O3 methanol-based fluid fuel is injected using the intake 
port, and diesel is injected into the cylinder. The test uses $M$ to represent the replacement rate of methanol/A12O3 methanol fluid to diesel in the DMDF mode. The calculation formula is as follows:

$$
\mathrm{M}=\frac{Q_{d}-Q_{m, d}}{Q_{d}} \times 100 \%
$$

Among them, $\mathrm{Q}_{\mathrm{d}}(\mathrm{kJ})$ and $\mathrm{Q}_{\mathrm{m}, \mathrm{d}}(\mathrm{kJ})$ represent the instantaneous mass consumption of diesel in pure diesel mode and DMDF mode, respectively. For example, M10 and M10A25 respectively represent methanol or nano-fluid fuel with a mass fraction of $25 \mathrm{ppm}$ in the dual-fuel mixture undergoing combustion, and the mass substitution rate of diesel to diesel is $10 \%$. The fuel consumption rate in DFDM mode is given by the following formula:

$$
\mathrm{BSFC}=\frac{Q_{m, d} \times Q_{L H V, d}+Q_{m, a} \times Q_{L H V, a}}{Q_{L H V, d} \times P_{b}} \times 100 \%
$$

The Qm,d indicates the instantaneous mass consumption of methanol-based fluid fuel in DFDM mode. Q $\mathrm{LHV}, \mathrm{d}$ and $\mathrm{Q}_{\mathrm{LHV}, \mathrm{a}}$ indicat the low calorific values of diesel and methanol, respectively; $\mathrm{P}_{\mathrm{b}}$ is the effective power of the engine.

The combustion and emission parameters $\mathrm{r} / \mathrm{min}$ diesel engine at different throttle opening $(10 \%, 30 \%, 50 \%, 70 \%$ and $90 \%)$ and different fuels (i.e. D100, M10, M10A25, M10A50 and M10A100) were measured at 1000 and $1800 \mathrm{rpm}$. The three parameters are measured after the diesel engine is running stably under the corresponding working conditions, and the arithmetic mean value is taken as the final data.

\section{Results and analysis}

\subsection{Combustion characteristics}

Fig .3 a-c shows the in-cylinder pressure and instantaneous exothermic rate curves of each fuel of diesel engine under different working conditions. It can be seen that the cylinder pressure and heat release rate curves of all fuel combustion are similar, indicating that each fuel has undergone the premixed combustion stage and the diffusion combustion stage. In order to further compare the combustion situation in each fuel cylinder, the peak pressure in the cylinder and the peak heat release rate are now compared, as shown in Figures 4 and 5. The results show that the high latent heat of vaporization and low evaporation temperature of methanol make the combustion start of DMDF combustion mode later than D100 under all working conditions. Under low load $(10 \%, 30 \%, 50 \%)$ working conditions, the peak pressure of M10 cylinder is lower than D100; while under high load (70\%, 90\%) working conditions, the peak pressure of M10 cylinder is higher than D100. This is because the temperature in the cylinder is lower under low-load conditions. Further evaporation of methanol reduces the temperature in the cylinder. The atomization of fuel and the formation of mixed gas are poor, which reduces the combustion pressure in the cylinder. 

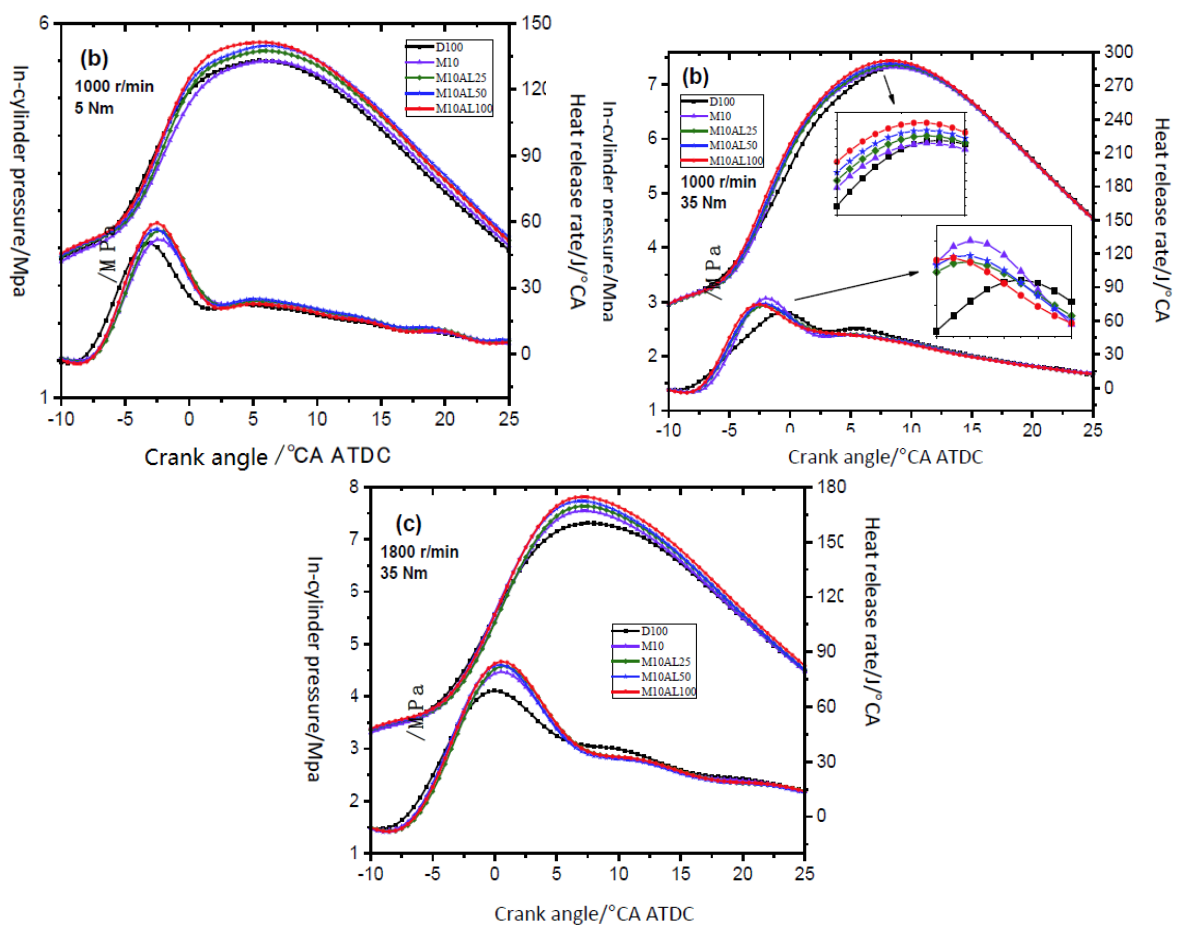

Fig. 3. Curves of pressure and heat release rate in fuel cylinders at different loads and speeds.
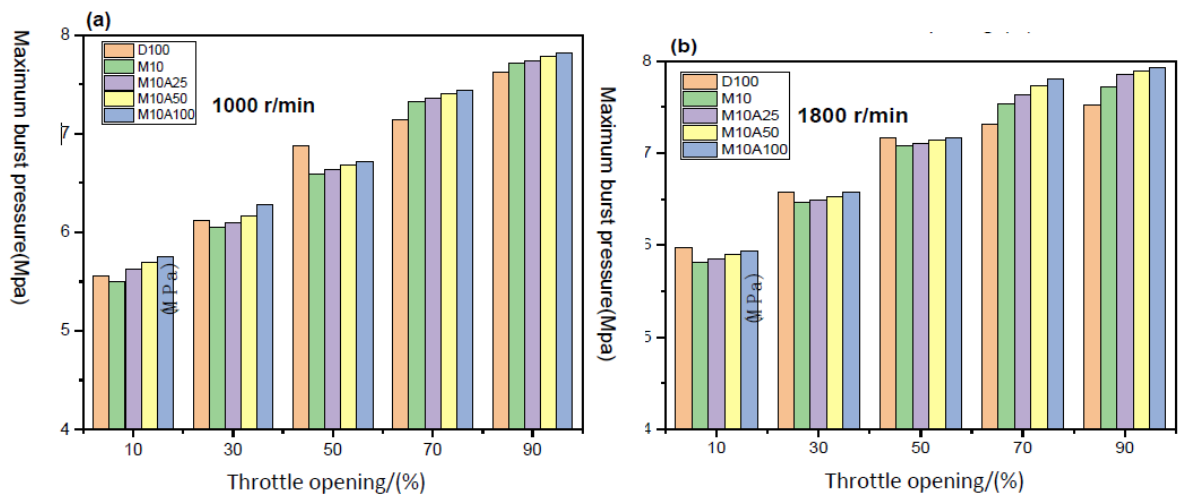

Fig. 4. The maximum burst pressure of each fuel at different loads and speeds.

As the load increases, the temperature in the cylinder will increase, which will weaken the adverse effect of methanol on the overall fuel and air mixing, and methanol increases the oxygen content of the fuel ${ }^{[10]}$, which makes the fuel in the DMDF combustion mode. Combustion is faster and more complete, resulting in better peak pressure in the cylinder. It can be found that the peak value of the M10 combustion heat release rate is higher than D100 under various operating conditions. This is because methanol can reduce the intake air temperature, which can increase the charge factor, improve the mixing effect of fuel and air, and increase its preparation during the ignition delay. The amount of combustible mixture ${ }^{[11,12]}$ can be calculated as compared with D100, the peak heat release rate of M10 is increased by a maximum of $4.32 \%$. When $\mathrm{Al}_{2} \mathrm{O}_{3}$ nanoparticles were added to methanol, the pressure in the cylinder of the diesel engine and the peak instantaneous heat release rate were significantly improved. Compared with $\mathrm{M} 10$, in the process of increasing the 
concentration of $\mathrm{Al}_{2} \mathrm{O}_{3}$ nanoparticles from $0 \mathrm{ppm}$ to $100 \mathrm{ppm}$, the peak pressure in the cylinders of M10A25, M10A50 and M10A100 continued to rise slightly and the combustion start point was advanced. This is the result of the catalytic combustion of Al2O3 nanoparticles. Compared with the M10, the M10A100's in-cylinder pressure and peak heat release rate have been increased by a maximum of $3.6 \%$ and $7.12 \%$. This is because the adhesion bond between fuel molecules and $\mathrm{Al}_{2} \mathrm{O}_{3}$ nanoparticles produces denser droplets and ligaments, which improves the atomization effect of methanol-based nanofluid fuel injection ${ }^{[13]}$. In addition, $\mathrm{Al}_{2} \mathrm{O}_{3}$ particles can improve the thermal conductivity of fuel, and accelerate the evaporation and mixing of fuel and air ${ }^{[14]}$. Under the combined effect of two aspects, the combustion effect of dual fuel has been greatly improved.
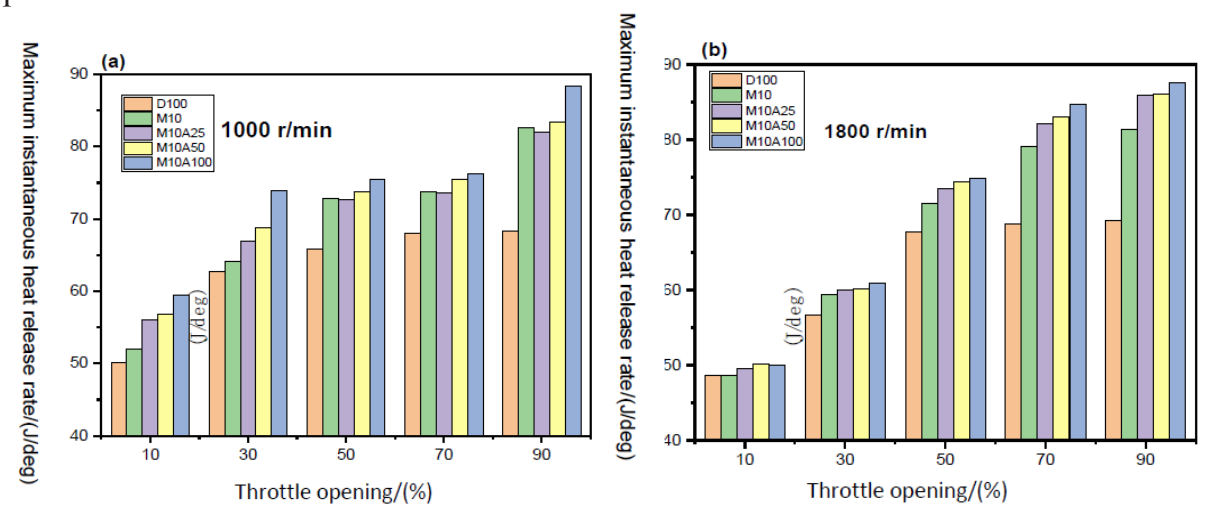

Fig. 5. Maximum instantaneous exothermic efficiency of each fuel at different loads and speeds.

Fig .6 shows the variation of different fuels at different loads and rotational speeds. The demurrage period of each fuel decreases with the increase of load under different working conditions, because the continuous temperature rise in the cylinder makes the fuel more easily evaporated, mixed and burned, thus shortening the demurrage period of diesel molecules ${ }^{[15]}$. The increase of rotational speed will further reduce the demurrage period, which is due to the higher temperature in the cylinder at high rotational speed. It can be seen from the figure that the delayed combustion period of the M10 is slightly higher D100, which is due to the lower in-cylinder temperature due to the higher vaporization latent heat of methanol and the lower methanol cetane number than diesel oil. The addition of nanoparticles shortened the demurrage period, and with the increase of particle concentration, the demurrage period of dual fuels was obviously shortened, and the maximum decrease was $6.17 \%$. This may be due to the small particle size of $\mathrm{Al}_{2} \mathrm{O}_{3}$ nanoparticles, and its large surface energy promotes the collision between particles and fuel droplets, and the thermal conductivity of diesel molecules increases, thereby weakening the adverse effects of methanol.

Fig .7 shows the variation of the combustion duration of each fuel in a diesel engine under different operating conditions (the crankshaft angle corresponding to the starting combustion of the fuel mixture to $95 \%$ of the fuel has been burned). It can be seen that the fuel injection amount of diesel engine increases with the increase of load, and the combustion duration of each fuel increases. Double fuel combustion duration is lower than D100, double fuel combustion duration is shorter due to two reasons: one is the low evaporation temperature and large specific heat capacity of methanol, which can provide longer evaporation mixing time for fuel. Furthermore, it increases the oxygen content of the mixture, which makes the combustion process of the mixture more rapid, especially in the starting stage, and the pressure rise rate of the mixed fuel is higher; The second is the promotion of $\mathrm{Al}_{2} \mathrm{O}_{3}$ nanoparticles on fuel evaporation combustion. In addition, the 
combustion duration of fuel at high speed is slightly lower than that of low speed, because the mixing speed of fuel and air is faster and the combustion speed also increases ${ }^{[16]}$. The burning duration of the M10A100 decreased by $6.74 \%$ and $7.30 \% \mathrm{rpm}$ the rotation speed of 1000 and 1800 respectively.
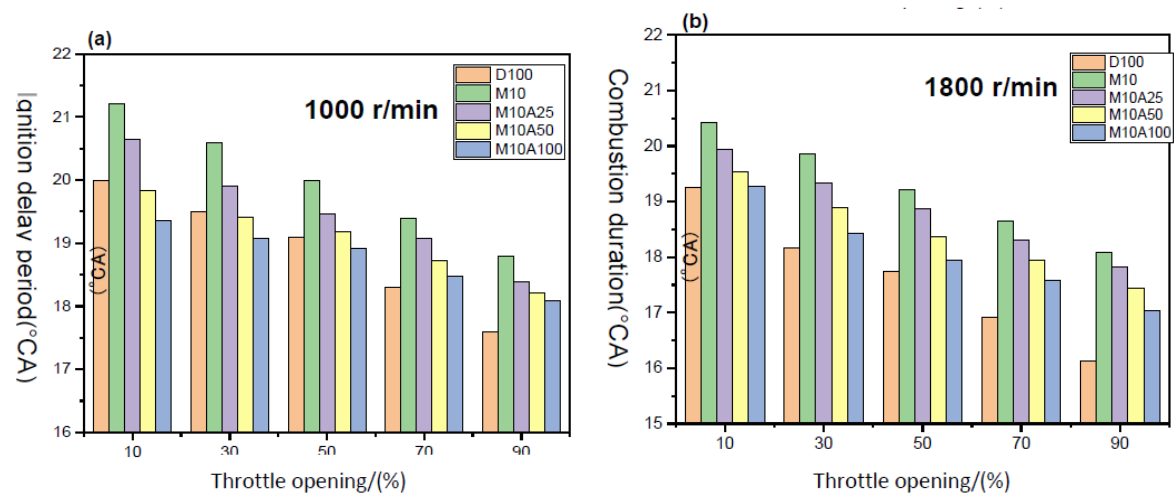

Fig. 6. The demurrage period of each fuel at different loads and speeds.
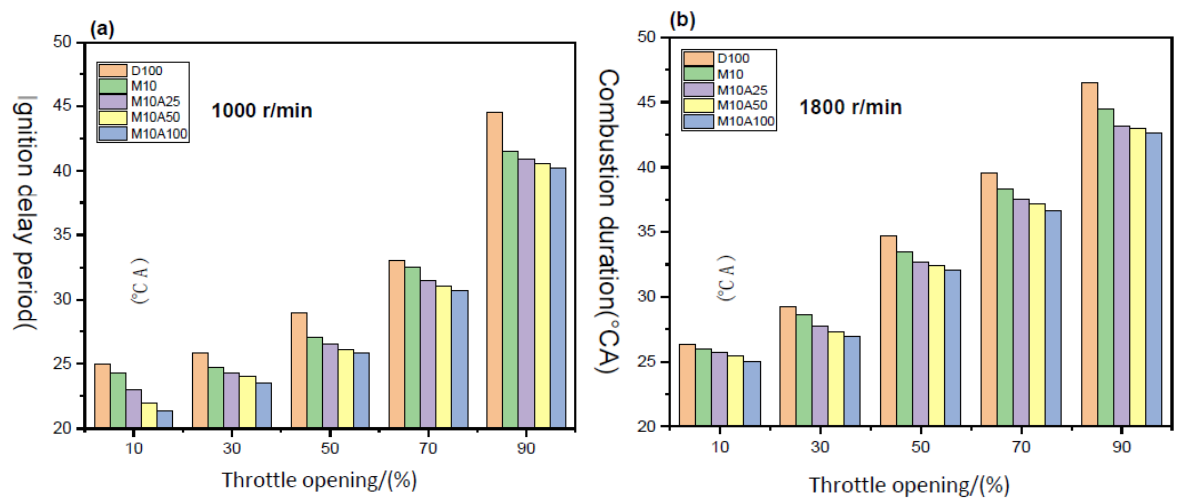

Fig. 7. Combustion duration of each fuel at different loads and speeds.

The relationship between the braking thermal efficiency of each fuel under different operating conditions in a diesel engine is shown in Figure 8. It can be observed that the thermal efficiency of each fuel increases continuously with the increase of engine load. The reason is that as the load increases, the temperature in the cylinder increases, which is conducive to the full release of fuel chemical energy. The increase in engine speed reduces the thermal efficiency of the engine brake. Although the higher temperature in the engine cylinder at high speed is beneficial to fuel combustion, the increase in engine speed significantly reduces the available time for fuel combustion, resulting in a reduction in engine thermal efficiency. The thermal efficiency of burning M10 is slightly higher than that of D100, this is because the oxygen-containing characteristics of methanol improve the combustion speed of the mixture, thereby improving the brake thermal efficiency. Compared with M10, the thermal efficiency of methanol-based nanofluid fuels with three concentrations gradually increases with the increase of particle concentration, and the thermal efficiency is increased by a maximum of $12.11 \%$. The reason is that the nanoparticles make the fuel have a large surface area to volume ratio, which can provide better atomization and rapid evaporation of the fuel ${ }^{[17]}$, and can also be used as a catalyst in the entire combustion process ${ }^{[18]}$. 

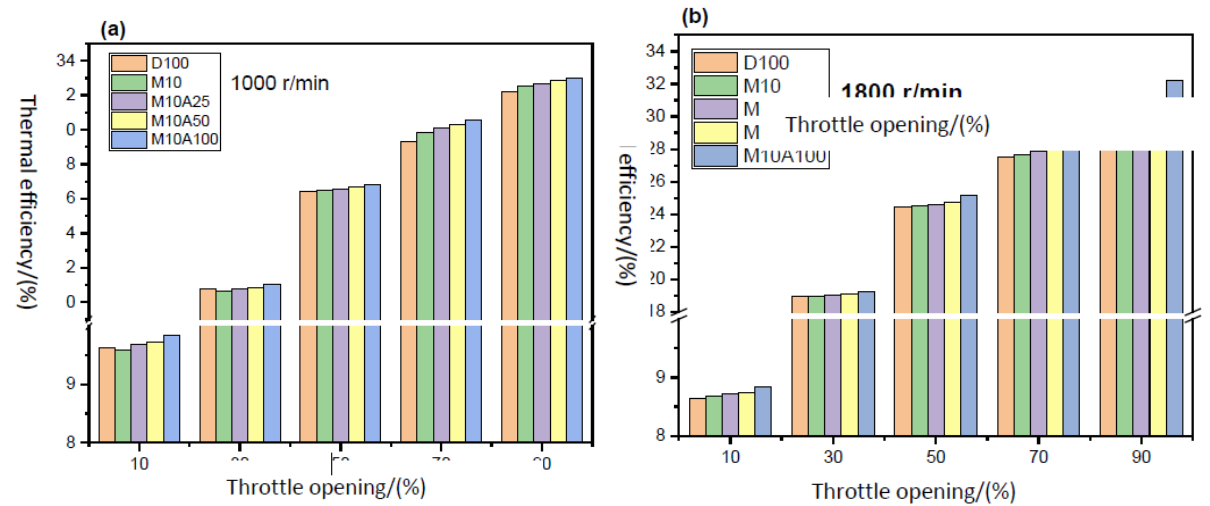

Fig. 8. Thermal efficiency of each fuel at different loads and speeds.

Fuel specific fuel consumption indicates the quality of the fuel consumed by the engine per kilowatt hour. Fig .9 shows the variation of fuel consumption rate in diesel engine under different working conditions. It can be seen from the diagram that at high speed, the engine unit cycle time is shortened, as shown above, the engine combustion thermal efficiency is lower than the low load, so the increase of engine speed leads to the increase of fuel consumption rate in the cylinder. At different rotational speeds, the fuel consumption rate of each fuel decreases greatly with the increase of load. the fuel consumption rate of M10 is slightly higher at low load D100, this is because the calorific value of methanol is low, resulting in the fuel quality consumption that emits the same power is greater than that of pure diesel. while at high loads, higher in-cylinder temperatures shorten the ignition delay (effect of methanol) of the dual fuel mixture, and higher oxygen content can accelerate the combustion process, which makes M10 fuel consumption lower than D100.. the fuel consumption rate is lower than that of M10,M10A25,M10A50 and M10A100 because the nanoparticles contained in them can reduce the size of fuel droplets, increase the thermal conductivity of the mixture, accelerate its evaporation mixing, and improve the combustion process. Among them, the largest drop in $\mathrm{M} 10 \mathrm{~A} 100$ was $10.8 \%$. The study found that $\mathrm{Al}_{2} \mathrm{O}_{3}$ nanoparticles have different effects on the specific fuel consumption of different fuels. Harish Venu et al. ${ }^{[19]}$ found that the fuel consumption rate of biodiesel-ethanol mixed fuel with $\mathrm{Al}_{2} \mathrm{O}_{3}$ particles decreased by a maximum of $8.42 \%$. However, Aalam et al. ${ }^{[20]}$ added nano $\mathrm{Al}_{2} \mathrm{O}_{3}$ to the methyl ester/diesel blended fuel, and the results showed that the fuel consumption rate was reduced by $6 \%$.
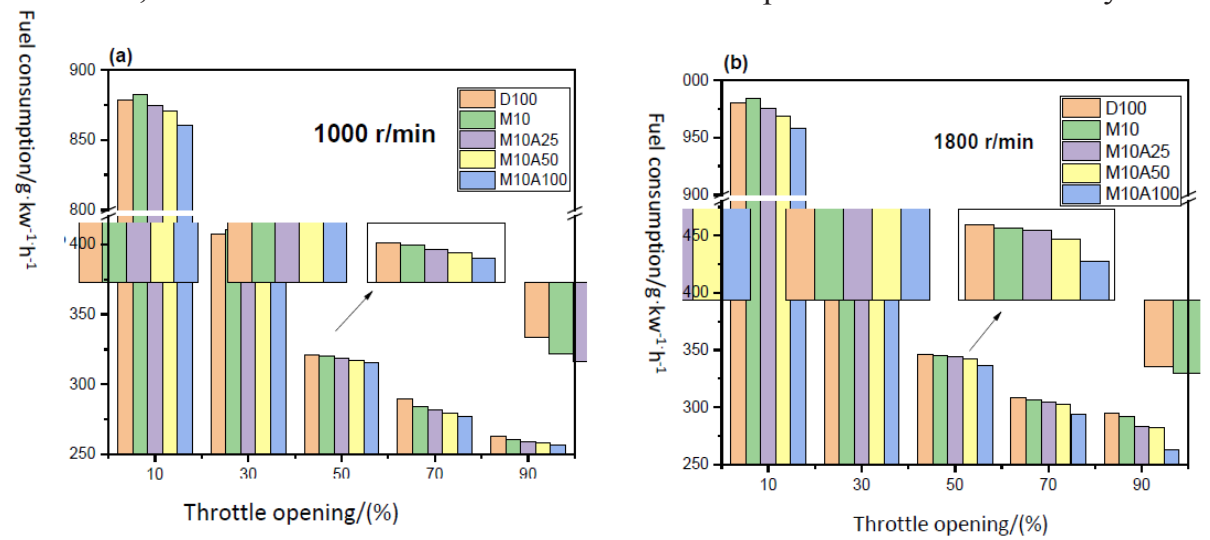

Fig. 9. Specific fuel consumption at different loads and speeds. 


\subsection{Emission characteristics}

$\mathrm{CO}$ is the inevitable product of incomplete combustion of the engine, but also reflects the degree of chemical energy loss.figure 10 shows the $\mathrm{CO}$ specific emission variation relationship of each fuel under different rotating speed and load. it can be seen from the figure that the $\mathrm{CO}$ specific emissions show a change trend of first decreasing and then increasing with the increase of load, and the lowest point of $\mathrm{CO}$ emissions appears in the medium load condition, while at low and high load CO the specific emission increases. Because of this phenomenon, under low and high load, diesel engine mixture concentration is large, so the combustion is not complete, will produce more CO. High CO emissions will occur in rarefied flame combustion zone under low load condition, hypoxia in jet core under high load condition, impact fuel on cylinder wall and end of jet fuel ${ }^{[21]}$. The comparison shows that the M10 D100 CO is higher than the emission under each load. This may be because methanol evaporates heat to reduce the temperature in the cylinder, so that the overall combustion integrity of the fuel decreased. nevertheless, the CO of M10 combustion emission is lower under low rotational speed and high load D100, which is probably due to the increase of engine in-cylinder temperature and combustion time under low rotational speed and high load, which is beneficial to the oxidation elimination of CO. Moreover, compared with M10,M10A25, M10A50 and M10A100, the CO ratio emission decreased by a certain extent, and the decrease increased with the increase of particulate concentration. Among them, the $\mathrm{CO}$ ratio emissions of the three groups of fuels decreased by $50.06 \%, 66.67 \%$ and $83.33 \%$ respectively. This is because the interaction between $\mathrm{Al}_{2} \mathrm{O}_{3}$ nanoparticles and fuel molecules destroys the homogeneity of the fuel, which can form a better air-fuel mixture, improve the combustion process, and reduce the generation of CO. In addition, the catalytic activity of $\mathrm{Al}_{2} \mathrm{O}_{3}$ nanoparticles for combustion can reduce the combustion activation temperature of carbon, alleviating the effect of reducing the incylinder temperature due to the evaporation endotherm of methanol, so that the combustion start point of the mixed gas is ahead of M10, and the combustion duration is longer. This will increase the completeness of combustion and reduce $\mathrm{CO}$ emissions ${ }^{[22]}$.
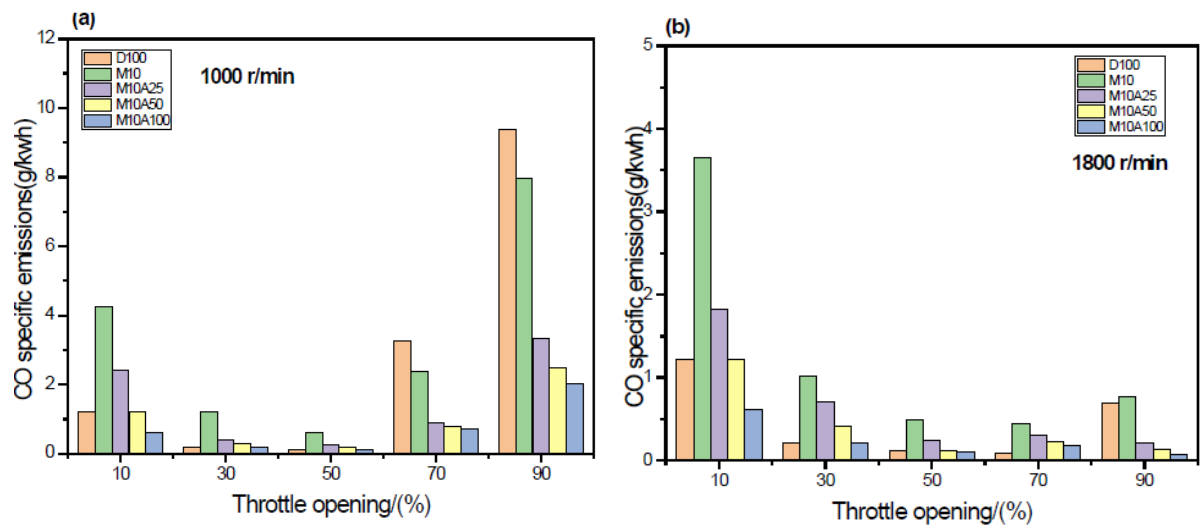

Figure $10 \mathrm{CO}$ ratios of fuel emissions at different loads and speeds

A specific emission change relationship $\mathrm{HC}$ different fuel conditions is shown in Figure 11. As you can see from the diagram, as the diesel engine load increases, the specific emissions HC each fuel gradually decrease. This is due to the increased load, The braking power of diesel engine has increased greatly, Although the increase in fuel injection reduces fuel combustion, An increase in unburned $\mathrm{HC}$ concentrations, But its specific emissions are gradually decreasing. Speed increases, $\mathrm{HC}$ emissions are decreasing, And this may be because higher speeds and higher temperatures accelerate the combustion of HC 
fuel, At the same time, the gas movement in the cylinder is enhanced at high speed, To burn the thinner mixture, and thus reduce the emission of unburned HC. D100, comparison The $\mathrm{HC}$ ratio of M10 was significantly higher, Because of the low boiling point of methanol and the high latent heat of vaporization, It will form a low temperature, low concentration mixture with the surrounding diesel steam and air, Which makes it hard to burn the fuel completely, HC generation increased. Compared to M10,. The HC ratio emissions of M10A25, M10A50 and M10A100 decreased significantly with the increase of particulate concentration. and its $\mathrm{HC}$ ratio emissions decreased by $57.66 \%, 61.26 \%$ and $73.50 \%$ respectively. Because $\mathrm{Al}_{2} \mathrm{O}_{3}$ nanoparticles enhance the mass transfer thermal conductivity of methanol/diesel dual fuels and inhibit the formation of low-temperature, over-thin mixture gas regions, thus reducing HC formation. S. Karthikeyan et al. [23] believe that nanoparticles can also act as catalysts during the combustion process to promote complete combustion of the mixture. After adding $\mathrm{Al}_{2} \mathrm{O}_{3}$ nanoparticles to $\mathrm{M} 10$, the emission reduction ratio to $\mathrm{HC}$ is about $60 \%$ under different working conditions, and the improvement effect is excellent.
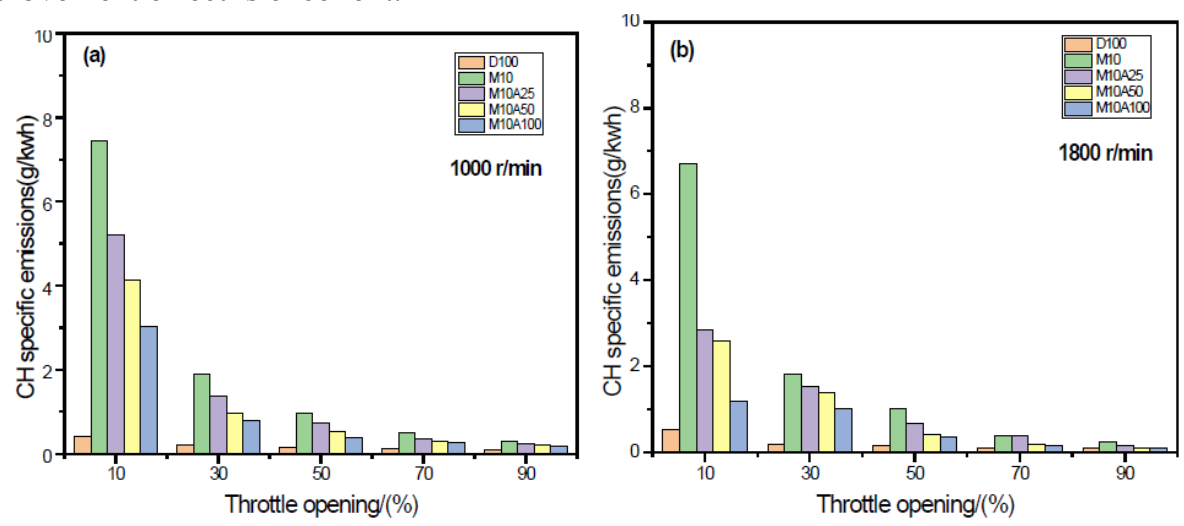

Figure $11 \mathrm{HC}$ ratios of fuel emissions at different loads and speeds

High temperature, oxygen-enriched and high temperature duration are the main factors leading to $\mathrm{NO}_{\mathrm{x}}$ formation. Figure 12 shows the $\mathrm{CO}$ ratio emissions of each fuel for diesel engine under different operating conditions. Overall, as the load gradually increases, the $\mathrm{NO}_{\mathrm{x}}$ specific emissions of the fuel gradually decrease as the load increases. The amount of $\mathrm{NO}_{\mathrm{x}}$ generated increases with increasing load, and the decrease in specific emissions is caused by the large increase in the braking power of the diesel engine as the load increases. By contrast, it is found that the $\mathrm{NO}_{\mathrm{x}}$ ratio of engine is higher than that of engine at low speed, which is mainly due to the long combustion time in engine cylinder and the small increase of engine power (the increase rate of $\mathrm{NO}_{\mathrm{x}}$ emission is higher than the rate of power increase). Under low load conditions, the $\mathrm{NO}_{\mathrm{x}}$ specific emission of $\mathrm{M} 10$ is obviously decreased compared with that of methanol, because the latent heat of vaporization reduces the temperature in the cylinder, which leads to the reduction of $\mathrm{NO}_{\mathrm{x}}$ production. With the increase of the load, the cooling effect of methanol is weakened by the increasing in-cylinder temperature, so the lower M10 NO $\mathrm{N}_{\mathrm{x}}$ than the emission under high load. Moreover, compared with the $\mathrm{NO}_{\mathrm{x}}$ specific emissions of M10,M10A25, M10A50 and M10A100, the decrease is slightly increased with the increase of particulate concentration. According to the previous analysis, $\mathrm{Al}_{2} \mathrm{O}_{3}$ nanoparticles can increase the thermal conductivity and cetane number of mixed 
fuel and increase the surface volume ratio of fuel. All these characteristics will increase fuel combustion integrity, increase in in-cylinder temperature and peak pressure, resulting in increased $\mathrm{NO}_{\mathrm{x}}$ production ${ }^{[23]}$. However, this also increases the output power of the diesel engine, and the combined effect of the two makes the $\mathrm{NO}_{\mathrm{x}}$ specific emission lower.
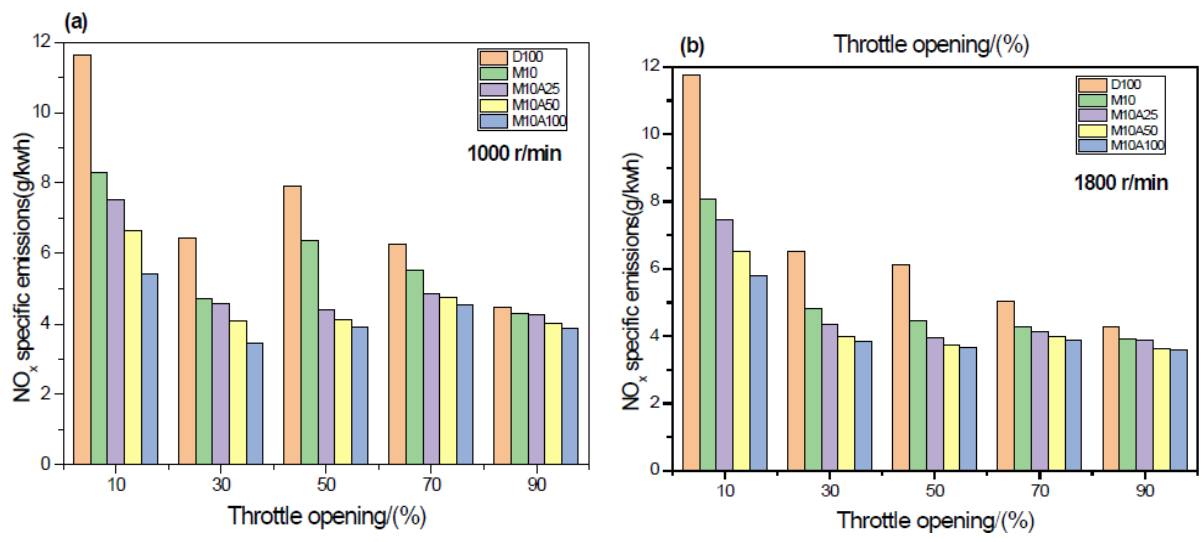

Figure $12 \mathrm{NO}_{\mathrm{x}}$ ratios of fuel emissions at different loads and speeds

Incomplete combustion of hydrocarbons and partial reaction of carbon atoms in fuels are the main sources of soot formation. Figure 13 shows the soot concentration emissions of each fuel under different operating conditions. On the whole, the soot emission concentration of each fuel increases significantly with the increase of load. This is because the amount of fuel injection increases with the increase of load, so the mixture of fuel and air is too rich, and the duration of fuel injection also increases. The load increases and prolongs, which increases the proportion of diffusion combustion. Both of these will increase the proportion of incomplete combustion of fuel and increase the concentration of soot emissions. The increase of rotational speed reduces soot concentration emission, which is mainly due to the increase of temperature in the cylinder is beneficial to soot oxidation. The emission concentration of soot is slightly higher than that of D100,M10 at low load, but at high load it is much lower than that of D100.. Because of this phenomenon, under low load, the amount of fuel injected is less, and the high vaporization latent heat of methanol will cause a long ignition delay, which will cause the ignition delay of the fuel, and then make the combustion effect of the fuel itself worse, resulting in the production of soot higher than the D100 and at high loading, methanol can promote effective combustion and reduce smoke generation because of its abundant oxygen and $\mathrm{OH}$ concentration. It can delay the ignition of the mixed gas, prolong the premixing process, reduce the amount of diffusion combustion, and reduce the generation of carbon nuclei. 

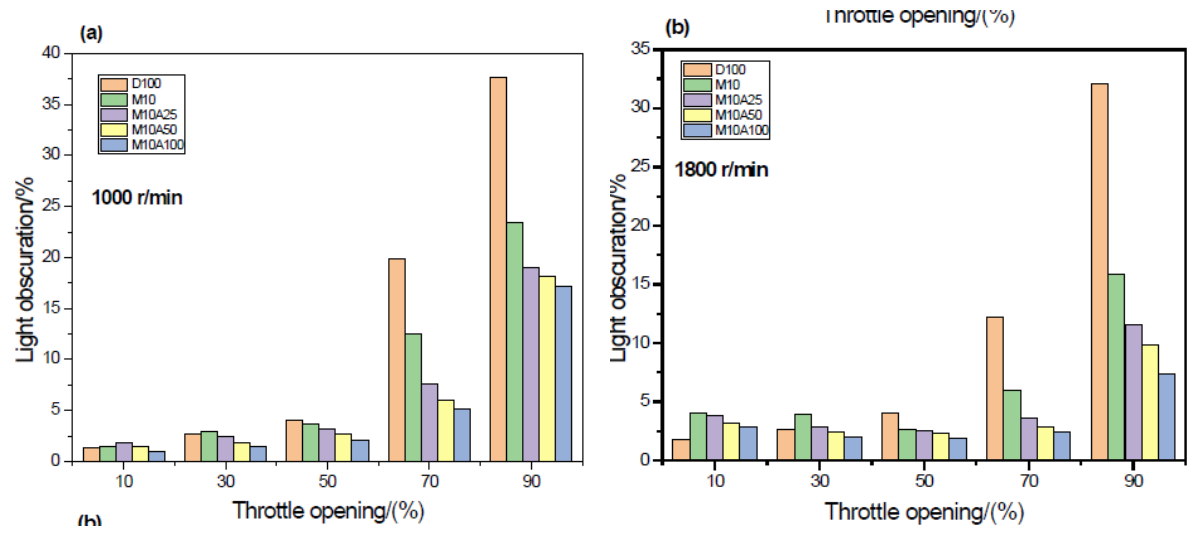

Fig. 13. Emissions of soot concentrations from fuels at different loads and speeds (impermeability).

Compared with M10, the soot emissions of M10A25, M10A50 and M10A100 with added nanoparticles all showed a decreasing trend, and as the concentration of particles increased, the decrease was greater. The soot emissions of the three fuels decreased by an average of $7.32 \%, 21.96 \%$ and $29.27 \%$ year-on-year. The reason is that $\mathrm{Al}_{2} \mathrm{O}_{3}$ nanoparticles can accelerate the atomization of fuel and reduce the uneven mixing of fuel and air. On the other hand, its large surface area to volume ratio is such that the fuel and air can fully contact. Both of them make the mixture burn more fully, thereby reducing the generation of soot. $\mathrm{Al}_{2} \mathrm{O}_{3}$ nanoparticles can also reduce the delay of fuel explosion, leading to a reduction in the amount of fuel accumulation in the combustion chamber, which in turn promotes the complete combustion of the fuel ${ }^{[24]}$.

\section{Conclusions}

(1) Under low load, the maximum burst pressure decreases with adding methanol, and the maximum instantaneous heat release efficiency changes little. Under high load, the maximum burst pressure slightly increases and the peak instantaneous heat release efficiency increases significantly. The addition of methanol prolonged the premixing time of the fuel and accelerated its combustion process. At $1000 \mathrm{r} / \mathrm{min}$, the demurrage period increased and the combustion duration shortened, this phenomenon was more obvious at $1800 \mathrm{r} / \mathrm{min}$. The addition of $\mathrm{Al}_{2} \mathrm{O}_{3}$ nanoparticles optimizes the combustion of methanol and diesel, so that the maximum burst pressure and the maximum instantaneous heat release rate in the cylinder increase, and the lag period and combustion duration are shortened. And with the increase of particulate concentration, the better the optimization effect is.

(2) In the DMDF mode, the fuel consumption rate of diesel engine increases at low load and decreases at high load. The change of thermal efficiency is opposite to the fuel consumption rate, which decreases slightly at low load and increases at high load. After adding $\mathrm{Al}_{2} \mathrm{O}_{3}$ nanoparticles to methanol, the fuel consumption rate decreased and the thermal efficiency also increased to a certain extent, indicating that $\mathrm{Al}_{2} \mathrm{O}_{3}$ nanoparticles can improve the fuel economy of methanol/diesel dual fuel. As the concentration of particulate matter increases, this increase is even greater. In addition, the $\mathrm{Al}_{2} \mathrm{O}_{3}$ nanoparticles increase the combustion thermal efficiency of the fuel and increase the actual heat release of the fuel, which also causes the exhaust temperature to rise.

(3) Under the methanol/diesel dual-fuel mode, CO specific emissions, HC specific emissions increased significantly compared to diesel, and $\mathrm{NO}_{\mathrm{X}}$ emissions and soot emissions decreased. When using methyl $\mathrm{Al}_{2} \mathrm{O}_{3}$ nano-fluid fuels instead of methanol, the 
emission of engine $\mathrm{CO}, \mathrm{HC}$ and soot decrease in different degrees, and with the concentration of nano $\mathrm{Al}_{2} \mathrm{O}_{3}$ increased, the overall decrease was greater.

(4) In summary, the use of methyl $\mathrm{Al}_{2} \mathrm{O}_{3}$ nanofluid/diesel dual fuel can reduce various common pollutant emissions during engine operation, increase its brake thermal efficiency, and reduce fuel consumption rate. The use of the two raw materials themselves will not increase the cost of fuel, which is conducive to the promotion of use.

\section{References}

1. Vellaiyan, S. and K.S. Amirthagadeswaran, Influence of Water-in-Diesel Emulsion Fuel and Compression Ratio on Combustion, Performance and Emission Characteristics of Diesel Engine. Sciendo, 2016. 3(3).

2. Hairuddin, A.A., T. Yusaf, and A.P. Wandel, A review of hydrogen and natural gas addition in diesel HCCI engines. Renewable and Sustainable Energy Reviews, 2014. 32: p. 739-761.

3. Kumar, V., et al., Production of biodiesel and bioethanol using algal biomass harvested from fresh water river. Renewable Energy, 2018. 116: p. 606-612.

4. Huang, Z., et al., Combustion behaviors of a compression-ignition engine fuelled with diesel/methanol blends under various fuel delivery advance angles. Bioresource Technology, 2004. 95(3): p. 331-341.

5. Chen, C., et al., Study of the characteristics of PM and the correlation of soot and smoke opacity on the diesel methanol dual fuel engine. Applied Thermal Engineering, 2019. 148: p. 391-403.

6. Zhang, Z.H., et al., Effect of fumigation methanol and ethanol on the gaseous and particulate emissions of a direct-injection diesel engine. Atmospheric Environment, 2011. 45(11): p. 2001-2008.

7. Fang Ping, et al., Nano- $\mathrm{CeO}_{2}$-based solid solution catalyzed combustion of carbon particles in diesel engines (in English). Chinese Journal of Physical Chemistry, 2007(08): p. 1275-1280.

8. Venu, H. and V. Madhavan, Effect of $\mathrm{Al}_{2} \mathrm{O}_{3}$ nanoparticles in biodiesel-diesel-ethanol blends at various injection strategies: Performance, combustion and emission characteristics. Fuel, 2016. 186.

9. Khatri, D. and R. Goyal, Effects of silicon dioxide nanoparticles on the performance and emission features at different injection timings using water diesel emulsified fuel. Energy Conversion and Management, 2020. 205.

10. $\mathrm{Wu}, \mathrm{T}$, et al., Effect of diesel late-injection on combustion and emissions characteristics of diesel/methanol dual fuel engine. Fuel, 2018. 233: p. 317-327.

11. Yao Chunde, et al., Experimental study on the effect of different methanol substitution ratios on DMCC emissions. Journal of Internal Combustion Engines, 2008(02): p. 134139.

12. Ning, L., et al., A comparative study on the combustion and emissions of a non-road common rail diesel engine fueled with primary alcohol fuels (methanol, ethanol, and nbutanol)/diesel dual fuel. Fuel, 2020. 266: p. 117034.

13. Soukht Saraee, H., et al., Reduction of emissions and fuel consumption in a compression ignition engine using nanoparticles. International Journal of Environmental Science and Technology, 2015. 12(7): p. 2245-2252. 
14. Li, Z., et al., Effects of diesel and methanol injection timing on combustion, performance, and emissions of a diesel engine fueled with directly injected methanol and pilot diesel. Applied Thermal Engineering, 2019. 163: p. 114234.

15. Wu Qimin, et al., Nano fuel additive $\mathrm{CeO}_{2}$ improves diesel combustion efficiency and reduces emissions. Journal of Agricultural Engineering, 2013. 29(09): p. 64-69.

16. Wei, L., et al., Combustion and emission characteristics of a turbocharged diesel engine using high premixed ratio of methanol and diesel fuel. Fuel, 2015. 140: p. 156163.

17. Nanthagopal, K., et al., Influence on the effect of zinc oxide and titanium dioxide nanoparticles as an additive with Calophyllum inophyllum methyl ester in a CI engine. Energy Conversion and Management, 2017. 146: p. 8-19.

18. Annamalai, M., et al., An assessment on performance, combustion and emission behavior of a diesel engine powered by ceria nanoparticle blended emulsified biofuel. Energy Conversion and Management, 2016. 123: p. 372-380.

19. Venu, H. and V. Madhavan, Effect of $\mathrm{Al}_{2} \mathrm{O}_{3}$ nanoparticles in biodiesel-diesel-ethanol blends at various injection strategies: Performance, combustion and emission characteristics. Fuel, 2016. 186: p. 176-189.

20. Aalam, C.S., C.G. Saravanan, and M. Kannan, Experimental investigations on a CRDI system assisted diesel engine fuelled with aluminium oxide nanoparticles blended biodiesel. Alexandria Engineering Journal, 2015. 54(3): p. 351-358.

21. Ithnin, A.M., et al., An overview of utilizing water-in-diesel emulsion fuel in diesel engine and its potential research study. Journal of the Energy Institute, 2014. 87(4): p. 273-288.

22. Vellaiyan, S. and C.M.A. Partheeban, Combined effect of water emulsion and $\mathrm{ZnO}$ nanoparticle on emissions pattern of soybean biodiesel fuelled diesel engine. Renewable Energy, 2020. 149: p. 1157-1166.

23. Karthikeyan, S., A. Elango, and A. Prathima, Diesel engine performance and emission analysis using canola oil methyl ester with the nano sized zinc oxide particles. Indian journal of engineering and materials sciences, 2014. 21(1): p. 83-87.

24. Shaafi, T. and R. Velraj, Influence of alumina nanoparticles, ethanol and isopropanol blend as additive with diesel - soybean biodiesel blend fuel: Combustion, engine performance and emissions. Renewable Energy, 2015. 80: p. 655-663. 